\title{
EL SOCIALISMO EN LA DICTADURA DE PRIMO DE RIVERA
}

\section{Por ENRIQUE GUERRERO \\ Universidad Complutense}

La Dictadura de Primo de Rivera no ha despertado hasta ahora demasiado interés entre los historiadores españoles. Despachada más o menos airosamente, pero en todo caso en forma breve, en los tratados generales, todavía hoy ofrece campo virgen a numerosas posibles monografias; aspectos tales como la Asamblea Nacional Consultiva y sus proyectos no consumados, la Unión Patriótica, nivel de implantación de la Organización Corporativa, un amplio estudio sobre el socialismo durante estos años, por citar unos cuantos, no están en absoluto desarrollados. Existe, no obstante, abundante bibliografia, aparecida en su mayor parte en los años inmediatamente posteriores a la caída del Dictador, pero en la que no faltan algunos trabajos de interés aparecidos recientemente. Parte de la misma aparecerá al pie de las siguientes páginas.

La Dictadura vino, según el Dictador, a poner pronto y radical remedio «a los asesinatos de prelados, ex-gobernadores, agentes de autoridad, patronos, capataces y obreros; audaces e impunes atracos, depreciación de moneda, francachela de millones reservados, sospechosa politica arancelaria... rastreras intrigas políticas tomando por pretexto la tragedia de Marruecos, incertidumbre ante este gravísimo problema nacional, indisciplina social... descarada propaganda separatista, pasiones tendenciosas alrededor del problema de las responsabilidades...»(1). De esta forma parecía que los objetivos de Primo eran restaurar el orden público, procesar a Alba, pacificar Marruecos, frenar al catalanismo... y solucionar el problema de las responsabilidades que amenazaba al propio rey; motivo de repetidas crisis ministeriales, esta

(1) Manifiesto del Golpe de Estado. 
fue la bandera que dio un triunfo rotundo a los socialistas -en Madriden las elecciones a diputados a unas Cortes que habían sido disueltas en abril de 1923; bandera que, en opinión de Villanueva, era también la de la República (2).

Lejos de ser solución a "noventa días» a una serie de manifestaciones de la crisis en que se pudría el tinglado restauracionista, la Dictadura era, cabalmente, su lógica alternativa desde dentro. La dictadura civil, cuya posibilidad no dejó de barajarse en las más altas esferas, ofrecía sin duda, desde el primer momento, muchas más dificultades: no podía hacerse sino con gente del propio tinglado, hubiera tenido que contar con el Ejército en bloque y hubiera sido más peligrosa para la Monarquía y para el régimen. Protagonizándola el Ejército se salvaguardaba la impresión de «interinidad» necesaria para su máxima aceptación. Y fue ampliamente aceptada por los mismos sectores a cuyos representantes políticos venía a desplazar. Contribuyó a ello al cansancio general respecto del «antiguo régimen»; cansancio que propiciaba el «cirujano de hierro» costista, expresión, en su forma arbitrista, de todos los regeneracionismos que en este pais han sido. Por otra parte, señala García Delgado, se hacía necesaria para garantizar la continuidad de unos intereses y relaciones sociales gravemente amenazados como consecuencia del deterioro producido por la crisis de los primeros años veinte (3).

Fue precisamente la incapacidad de Primo de Rivera en crear una legalidad ex-novo o en conseguir un consensus en torno a unas reformas básicas de la existente - aunque suspendida- lo que provocó al final su caída, la de la Restauración a la que no supo dar salida, y la de la Monarquia, dando paso a una nueva relación de fuerzas concretada en el 14 de abril.

Raúl Morodo ha definido la Dictadura (4) como «la versión española del bonapartismo", el regeneracionismo llevado a cabo con la técnica bonapartista. Habría que precisar que la Dictadura capitaliza la conciencia regeneracionista, manifestada con distintas variantes en los más diversos sectores del país. Nuestros "regeneracionismos" no serían entendidos sin la Restauración y las «conciencias» de crisis que provoca el progresivo hundimiento de la misma. Pero a nivel político-institucional, la exigencia regeneracionista de autentificar las instituciones liberales, lo que implicaba extirpar las prácti-

(2) Francisco Villanueva: Obstáculos Tradicionales, primer tomo, Madrid s/f.

(3) José Luis García Delgado: Origenes y Desarrollo del Capitalismo en España. Notas Criticas. (La política fiscal de la Dictadura: el testimonio de Calvo Sotelo), Madrid 1975, pág. 208.

(4) Raúl Morodo: «El 18 brumario español. La dictadura de Primo de Rivera». Rev. Triunfo 15 set. 1973. 
cas de la Restauración, no será abordada más que tarde, incoherentemente $y$ con evidente fracaso, por Primo.

Indudablemente se llevaron a cabo planteamientos regeneracionistas; algunos puramente demagógicos como los de primera hora: disposiciones referentes a la puntualidad de los funcionarios, formalización de un indice de asuntos sin resolver ingresados en los centros ministeriales en el último quinquenio, el aliento a que se formulen públicamente quejas en los Ayuntamientos, etc., etc. Otros indudablemente serios, relacionados con el fomento económico, obras públicas por ejemplo. Tentativas de implantación institucional de concepciones organicistas, a las que no eran extraños ni siquiera socialistas influidos por el Krausismo. Incluso la versión pre-tecnocrática de afrontar problemas concretos no importa cual sea la estructura política. Pero en lo básico, repetimos, falló Primo de Rivera. Faltó el médico que sustituyera al «cirujano» y todo lo demás apareció incoherente.

Ramos Oliveira, en libro sumamente interesante por diversos conceptos (5), calificó a la Dictadura como «régimen coactivo de pura oligarquía» diferenciándola del fascismo como "dictadura de clase». No era un golpe de Estado de la burguesía sino una maniobra del Rey para salvarse. La argumentación era clara: la agudización de la lucha de clases no alcanzaba nivel peligroso para la burguesía, no había peligro revolucionario y por lo tanto no era necesario el fascismo, «contrarrevolución preventiva» como lo había calificado Fabri.

$\mathrm{Y}$ a pesar de que hubiese en los primeros momentos tendencias a asimilar nuestra dictadura con la italiana, éstas no podían acogerse sino a meras anécdotas: viaje con los Reyes a Italia en noviembre de 1923 y los mutuos halagos cruzados entre Primo y Mussolini a quien nuestro dictador quiso comparar el Somatén con el Partido; el siempre presente chiste coyuntural: «Primo de Rivera ma secondo di Mussolini» (6); el trato a favor que siempre tuvo el fascismo por parte de la censura (7). Y más tarde, sin duda, las influencias corporativas. Aunque, como ha señalado Manuel Pastor la Dictadura fue caldo de cultivo del futuro fascismo español (8), las distancias entre aquella y el fascismo eran abismales como veremos.

El notable crecimiento económico experimentado durante estos años no puede explicarse únicamente en base a la ola de general prosperidad caracteristica de la postguerra, los llamados por Lacomba «felices años

(5) Antonio Ramos Oliveira: Nosotros los marxistas. Lenin contra Marx, Madrid 1932.

(6) Salvador de Madariaga: España. Ensayo de Historia Contemporánea, Madrid 1931, pág. 277.

(7) Celedonio de Iglesia: La censura por dentro, Madrid s/f (1930).

(8) Manuel Pastor: Los origenes del fascismo en España, Madrid 1975. 
veinte», aunque sin duda se beneficiaba la misma. Antes bien, la Dictadura en si misma, en lo que respecta al mantenimiento del orden público, disminución de la conflictividad laboral y ante todo la política económica adoptada (9) explicaria, no solamente el crecimiento logrado sino el carácter del mismo y quienes fueron sus beneficiarios. Porque en efecto, tal política económica sigue los pasos de un profundo nacionalismo: creación del Monopolio de Petróleos, repatriación de divisas, fomento del consumo de artículos nacionales para el que incluso se llega a crear un Patronato en 1929, etc.; nacionalismo este que, según señala Garcia Delgado, prolonga e intensifica tendencias "progresivamente arraigadas y extendidas desde que se inicia el viraje proteccionista del capitalismo español en los primeros lustros de la Resturación [y que] adquieren una inusitada fuerza durante el periodo de 1914 a 1920» y viene a ligarse ahora a un fuerte intervencionismo y a un robustecimiento del sector público. De ahí que se haya considerado a la Dictadura como "primer brote de capitalismo de Estado".

Como habría dicho el propio Calvo Sotelo «las dictaduras propenden fatalmente al intervencionismo» (10). Este tenía ya antecedentes tanto en planteamientos regeneracionistas como en modestas intervenciones «desde el poder»: Maura y Cambó, por ejemplo. Ahora suponía, en mayor grado, abandono progresivo del abstencionismo liberal -que en sentido riguroso sólo existió en su formulación ideológica - en el campo económico. En otros aspectos la regulación por parte del Estado venía ya de muchos años atras. La decidida política de intervención, plasmada sobre todo en el vigoroso plan de obras públicas, jugando presupuestariamente, ha permitido hablar de adelanto, aun antes del crack del 29, a tesis Keynesianas.

Nacionalismo (11) e intervencionismo se complementan y conducen a una fuerte acumulación y concentración de capital durante estos años, medible especialmente en el rápido crecimiento de los mayores Bancos, como ha señalado Velarde, concentración de empresas, prácticas monopolistas, etc. Prácticas que conjuntadas con el apoyo al capital financiero y política «reaccionaria» (Velarde) con respecto al campo y unidas a una presión fiscal privilegiada de este con respecto a la industria, señalan por fin quienes

(9) Véase, entre otros. Juan Velarde Fuentes: Politica económica de la dictadura, Madrid 1968; García Delgado op. cit.; TuÑón DE LARA: El Movimiento Obrero en la Historia de España, Madrid 1972; Miguel Martínez Cuadrado: La burguesia conservadora (1874-1931), Madrid 1973.

(10) José Calvo Sonelo: Mis Servicios al Estado, Madrid 1931, pág. 256.

(11) Lo que no impide una cierta penetración de capital extranjero como señala TuÑón DE LARA, op. cit., pág. 751; Telefónica, Standard Eléctrica, General Motors, General Eléctrica, Nestlé, Philips Ibérica, Nacional Pirelli, entre otras empresas. 
son los mayores beneficiarios de la Dictadura y donde está su base de apoyo. También sus limitaciones y las relaciones de fuerza durante estos años.

Pero claramente las prácticas dictatoriales no iban más allá de la corrección de abstencionismos liberales. Lejos del «nada fuera del Estado" partían de la intervención de éste con carácter subsidiario (Calvo Sotelo). Primo de Rivera en el manifiesto de 5 de septiembre de 1926 en el que anuncia su intención de crear una Suprema Asamblea Nacional -así la llamará entonces - señala que el Gobierno tiene la concepción de un Estado "de nueva estructura, fuerte, real, práctica, democrática... pero no un Estado absorbente, centralizador, burocrático y entorpecedor, sino que estimule, inspeccione y favorezca». Primo se enorgullecía de la creación del Consejo de Economía Nacional — «no he dejado aún de dar gracias a Dios una noche por haberme[lo] inspirado"- asi como del Comité Regulador de la Producción; pero no hay que olvidar que a este último se oponía Calvo Sotelo (12).

Nada recuerda en la Unión Patriótica al partido fascista organizado férrea y jerárquicamente, omnipresente y omnipotente. Fue la U.P. una de las debilidades de Primo de Rivera a la que dedicó «esfuerzos magnos, gigantescos» (13). Aún así, ni siquiera el Dictador tuvo una idea clara de la finalidad a que pensaba destinar su criatura ni de la estructura con que dotarla. Pensada en 1924 con el fin temporal y concreto de heredar al Directorio (14), su entrada en escena quedó relegada, en las intenciones de Primo, a ser la heredera de la Dictadura (15). En el intermedio, sin embargo, la mayoría en las Diputaciones y Ayuntamientos debería pertenecer a la U.P., mientras correspondiese la designación a los Gobernadores. De igual forma se le concedia importante representación en la Asamblea Nacional Consultiva según el R-D-Ley que la creaba.

¿Cómo concebía Primo de Rivera a la U.P.? No es un partido, repetía,

(12) Comité Regulador en el que no creia Calvo Sotelo tal como se concibió (Calvo SoTElo op. cit., pág. 259).

(13) Calvo Sotelo, op. cit., pág. 332.

(14) El Pensamiento de Primo de Rivera. Sus notas, artículos y discursos. Prólogo de José M. ${ }^{\mathrm{a}}$ Pemán, Madrid, 1929, pág. 52.

(15) Asi lo afirmaba en carta dirigida por Primo de Rivera al jefe nacional de la U.P. José Gabilán, el 23 de junio de 1928, al tiempo que le pedia que, con ocasión del primer quinquenio de la Dictadura, expresase con «cifras contrastadas y comprobadas» «lo que ella es y los títulos que ostenta para proseguir la obra sin temores ni desmayos", y le trazaba un programa de 19 puntos, en base a los cuales se trazaria, poco después, el Decálogo de. la U.P. El Pensamiento... págs. 71 y ss. 
"es una conducta organizada», "una Asociación de hombres de buena fe, apolíticos o políticos, que no se hayan contaminados con los vicios pasados y que gocen de notoria honorabilidad». No iba el Directorio militar —decía en 1924 que derrocó las organizaciones políticas que actuaban en la vida pública, a crear otro organismo análogo a los caídos. $\mathrm{Y}$ a continuación, en una de esas intuiciones geniales que le sobrevenían a altas horas de la madrugada mientras preparaba las notas oficiosas añadía que debían integrarla itodos los que aceptasen la Constitución de 1876! «No somos una fuerza armada como el fascismo... somos virtualmente una cruzada civil saneadora.»

El poeta-prologuista-prologado-asambleísta José María Pemán en obra dedicada al tema (16), consideró a las U.P. como «gotas de democracia infiltradas en el régimen dictatorial» (17) así como «el pudor de la. Dictadura" (18), no sin insistir en la necesidad de que las U.P. no hiciesen política en el más viejo y peor sentido de la palabra, pues «la política, como todo lo humano, será siempre claudicable y pecadora» (19).

Aun a pesar de la indudable euforia que suponía el deseo de Primo de extender las U.P. a millares de españoles residentes en América y el sueño de Pemán de considerarlas como un "fenómeno mundial», estas nunca fueron tomadas demasiado en serio por quienes no fueran sus afiliados. Gabriel Maura, quien no estaba demasiado lejos, apuntó que «carecían de médula y de vértebras». Y fueron ministros de la Dictadura quienes, caida ésta, se refirieron a la U.P. como una obsesión y un error de su ex-presidente. Así Calvo Sotelo que vio -como Martínez Anido- con hondo recelo la iniciativa; «los partidos políticos - pensó- cuando se organizan desde el Poder y por el Poder nacen condenados a la infecundidad por falta de savia» (20); "entre los upetistas -añadió- al lado de los soldados de buena fe que rendían a la señora y al lema (21) sincera pleitesía, cancelatoria de antiguos compromisos políticos, los había profesionales del dolo o de la cuquería, que, llenos de reservas mentales, sólo habían rendido su cerviz en sumisión hipócrita e interesada». Concluía el ex-ministro señalan-

(16) José M." Pemán: El Hecho y la Idea de la Unión Patriótica Prólogo del General Primo de Rivera), Madrid 1929.

(17) Pemán, op. cit., pág. 19.

(18) Pemán, op. cit., pág. 28.

(19) Pemán, op. cit., pág. 59. A este respecto, una superficial lectura, en nuestros dias, de los medios informativos basta para comprobar la existencia de una linea de tradición que entronca a nuestra élite política con dichos postulados.

(20) Calvo Sotelo, op. cit., pág. 331 y ss.

(21) El lema era: «Patria, Religión, Monarquáa. 
do que lo más grave de la U.P. no fue ella en sí misma, sino el influjo funesto que en el ánimo de Primo ejercieron algunos de sus directivos. Por su parte Aunós (22), tras hacer hincapié en lo señalado por Calvo Sotelo aludía al «tono grisáceo, en sus mejores partes, y turbio en las restantes, que tuvo fatalmente el partido único (sic) de la U.P.». Cabe señalar no obstante, que en torno suyo (de la U.P.) se agruparon distintos sectores que más tarde, en otras circunstancias, derivarian hacia el fascismo.

Aspecto importante de la Dictadura es, sin duda, la Organización Corporativa aplicada a las relaciones de trabajo, establecida el 26 de noviembre de 1926, siendo Aunós ministro de Trabajo. Reclamaba Aunós como antecedentes la legislación laboral del Estado modificadora de los principios establecidos por la ley Chapelier (1791) que disolvió las asociaciones gremiales, así como la institucionalización generalizada en diversos países de la conciliación y el arbitraje para la resolución de conflictos laborales. Pero nuestra Organización estaba tan lejos del mero arbitraje como de la organización corporativa italiana, establecida por la ley de 3 de abril de 1926, que era su antecedente más inmediato y por la que Aunós sentía un indudable cariño (23). En la Italia fascista el individuo operaba en el sistema económico corporativo «según una voluntad guiada, directa... de forma que su actividad responda a los fines del Estado» (24); la libertad sindical, reafirmada con la Declaración tercera de la Carta del Lavoro se concilia aún «con la exigencia, debidamente reconocida, de la unidad sindical, corolario evidente de la unidad de la economia nacional corporativa, por la que sólo el sindicato legalmente reconocido y sometido al control del Estado tiene derecho a representar legalmente a toda la categoria de trabajadores y de empleadores por quienes está constituido" (25). Se establecía pues, de facto, la sindicación forzosa y solo podía elegir a la Corporación el sindicato reconocido, único, estatal.

Por el contrario aqui se establecía el principio de «sindicación libre y corporación obligatoria), lo que enraizaba con concepciones procedentes del corporativismo católico, y más lejos aún, con aspectos residuales del tradicionalismo. El Principio VIII del Programa Doctrinal y de Acción de la Confederación Nacional de Sindicatos Católicos de Obreros (1919) decía

(22) Eduardo Aunós: Itinerario Histórico de la España Contemporánea (1808-1936), Barcelona, 1940, págs. 385 y 386 .

(23) Eduardo Aunós: Las Corporaciones de Trabajo én el Estado Moderno, Madrid 1920, págs. 35 y ss.

(24) A. Serpierr: Principi di Economia Politica Corporativa, Firenze, 1938.

(25) Gino ARIas: Corso di Economia Politica Corporativa, Roma, 1938, págs. 403 y ss. 
así: «Rechazamos el Sindicato Unico obligatorio porque es instrumento de tiranía monstruosa. Nuestro lema en esta materia es: La Corporación obligatoria, pero el Sindicato libre» (26). Ya en 1929, entre las peticiones de los Católicos a los poderes públicos con motivo de la Fiesta del Trabajo, figura la de que «los obreros católicos amamos la organización corporativa como cosa nuestra, de nuestro ideario social».

Sin entrar en imposibles detenimientos, digamos esquemáticamente que el Decreto creaba 27 Corporaciones que representaban otros tantos sectores de producción. Su célula era el Comité Paritario local o interlocal de profesión (cinco obreros y cinco patronos, con un Presidente y Vicepresidente nombrados por el Ministerio de Trabajo, Comercio e Industria) con facultades para determinar las condiciones de reglamentación del trabajo, retribución, y las que puedan servir de base a los contratos de trabajo individuales y colectivos; a las Comisiones mixtas concurren profesiones diferentes pero enlazadas. El conjunto de Comités Paritarios de un mismo oficio existentes en el país constituyen la Corporación y su misión será el estudio de los jornales y salarios existentes en los distintos oficios para establecer un salario minimo por profesiones. Los Consejos de Corporaciones se constituyen con una representación de ocho vocales patronos y ocho obreros, elegidos por los Comités Paritarios que la forman. En la cumbre, la Comisión Delegada de Consejos, «supremo organismo de arbitraje y al mismo tiempo entidad de consulta para el Ministerio» en la que además de la representación obrera y patronal figura la del Estado (Presidente y el Director General de Trabajo).

Del R.-D.-Ley creador se exceptuaba las actividades agrarias, creadas por otro de 12 de marzo de 1928 por el que se instituían tres Corporaciones: la del Trabajo Rural, la de la Propiedad Rústica y la de la Industria Agrícola.

Ni las Industriales ni las Agrarias llegaron a funcionar plenamente, pero fueron bastante aceptadas, más por los obreros (sobre lo que insistiremos más adelante) que por los patrones. Al volver sobre ellas, Pemartín, en 1937, culpaba de su fracaso a no haberse seguido la «técnica corporativista italiana», a no haber "verticalizado» a obreros y patronos, uniéndolos en la Corporación, zona de convergencia, no en el Comité Paritario como se hizo (27).

A gran distancia pues la Dictadura del fascismo italiano, se lamentaba

(26) ANTONio EloRza: «Documentos sobre Sindicalismo católico obrero en España (1919-1938)", Rev. de Trabajo n. 33, Madrid, 1971, pág. 185.

(27) José Pemartín: Qué es lo Nuevo..., Sevilla 1937, pág. 381. 
Aunós en 1940 de que no se hubiese ido hacia adelante «a la manera mussoliniana», creando una doctrina nueva, forjando un partido prepotente y construyendo un Estado poderoso; por no hacerlo, concluía Aunós la Dictadura fue efimera.

Nivel de conflictividad

\begin{tabular}{lrrrcrc}
\hline Años & $\begin{array}{c}\dot{N}^{\circ}{ }^{\circ} \\
\text { huelgas }\end{array}$ & $\begin{array}{c}\text { Huel- } \\
\text { guistas }\end{array}$ & $\begin{array}{c}\text { Jornadas } \\
\text { perdidas }\end{array}$ & $\begin{array}{c}\% \text { ganadas } \\
\text { por huelgas }\end{array}$ & $\begin{array}{c}\% \\
\text { pérdidas }\end{array}$ & $\begin{array}{c}\% \\
\text { transigidas }\end{array}$ \\
\hline 1917 & 306 & 71.440 & 1.784 .538 & 26 & 29 & 45 \\
1918 & 463 & 109.168 & 1.819 .295 & 36 & 16 & 48 \\
1919 & 895 & 178.496 & 4.001 .278 & 30 & 17 & 53 \\
1920 & 1.060 & 244.684 & 7.261 .762 & 20 & 26 & 54 \\
1921 & 373 & 83.691 & 2.802 .299 & 16 & 34 & 48 \\
1922 & 487 & 119.417 & 2.672 .567 & 13 & 36 & 47 \\
1923 & 465 & 120.568 & 3.027 .026 & 13 & 43 & 40 \\
1924 & 166 & 28.744 & 604.512 & 13 & 33 & 52 \\
1925 & 181 & 60.120 & 839.934 & 17 & 38 & 45 \\
1926 & 96 & 21.851 & 247.223 & 12 & 41 & 47 \\
1927 & 107 & 70.616 & 1.311 .891 & 9 & 38 & 53 \\
1928 & 87 & 70.024 & 771.213 & 9 & 47 & 44 \\
1929 & 96 & 55.596 & 313.065 & 18 & 47 & 35 \\
\hline
\end{tabular}
1929.

Y «Estadísticas de las Huelgas». Memoria correspondiente al año 1929. Madrid 1932.

Ambas Memorias publicadas por el Ministerio de Trabajo. Dirección General de Trabajo.

Interpretando de forma global estos datos no cabe la menor duda de que el nivel de conflictividad laboral desciende de forma sensible durante los años de la Dictadura si los cotejanos con los de los seis años precedentes. 1923 sería la excepción, pero hay que tener en cuenta que la Dictadura llega ya a mediados de septiembre. Desciende en los índices más sensibles, es decir $\mathrm{n}^{\circ}$ de huelguistas y $\mathrm{n} .{ }^{\circ}$ de jornadas perdidas. La Memoria correspondiente a los años 1927 y 1928 afirmaba en su Introducción que los conflictos habian disminuido notablemente, presentando en general caracteres de contiendas que se producen sin grandes violencias: «mucho ha influido, sin duda, en esta disminución y apaciguamiento la labor de los Comités Paritarios. No es que la Organización Corporativa suprima las huelgas... pero evidentemente las ha disminuido $\mathrm{y}$, sobre todo, ha logrado su menor violencia». Afirmación algo gratuita si tenemos en cuenta que 1926 supone el techo más bajo y discurre todo él sin Organización Corporativa, pues ésta se establece en noviembre de dicho año. Por el contrario van a ser 1927 
y 1928 años de modesta recuperación, para volver a decaer en 1929 en que, ahora si, la Organización Corporativa tenía ya cierta implantación. Hay que precisar el punto más alto alcanzado en 1927, señalando que la huelga en la cuenca minera asturiana (1..$^{\circ}$ octubre a 4 de noviembre) supone por sí sola 500.000 jornadas perdidas y 20.024 huelguistas.

No menos curiosa resulta la afirmación contenida en la Memoria correspondiente al año 1929 y que, no hay que olvidar, se edita en 1932: «instaurada la Dictadura, la disminución en el número de anormalidades en los años 1924, 1925, 1926, 1927, 1928, y 1929 es "roficialmente» considerable. Efectivamente la situación del país no era la más propia para el desarrollo de los conflictos. No solamente la situación política, de evidente rigor para sofocar cualquier intento de huelga, apelando a procedimientos tan poco en consonancia con las normas de conciliación y arbitraje como las de encarcelamiento y deportación de los elementos directores $\mathbf{u}$ organizadores del conflicto. Además, parece haberse comprobado la ocultación, por parte de algunas Autoridades, de huelgas planteadas, acaso con el objeto de crear triunfos artificiales de organizaciones no bien maduradas o de novísimos procedimientos de arreglo" (páginas 11 y 12). Obviamente el hecho en sí de la Dictadura, se reflejaba en esa disminución que no era meramente "oficial», pero la última parte parece meramente una justificación; simplemente "parecía» haberse comprobado. Sin excluir, por supuesto, que se diesen ciertos casos, que no afectarían sustancialmente los datos.

En lo que toca a los socialistas - que no eran los únicos posibles huelguistas- su actitud con respecto al incremento huelguístico de los últimos años de la Dictadura, fue a nivel de dirección, como poco, muy prudente. Si bien el Congreso del Sindicato Minero apoyó en 1927 la huelga con la oposición de Llaneza, en muchos casos se escuchaba en la presencia de elementos no ugetistas para no secundarlas. Interesantes son, sin duda, dos artículos aparecidos en el Boletín de la U.G.T. en marzo y diciembre de 1929 firmados por Saborit y Cordero; en el primero de ellos "Ni presos ni huelguistas», el secretario del Partido y vicepresidente de la U.G.T. mantenía que sólo se podía ir a la huelga "cuando se dispone de fondos para sostener unas cuantas semanas a los huelguistas; cuando está asociada la mayoría del oficio, cuando hay trabajo abundante, cuando se cuenta con el apoyo previo de las organizaciones sindicales superiores y cuando han fracasado todas las gestiones de conciliación con patronos y autoridades». En el segundo "A propósito de la fusión y del frente único del proletariado» Cordero, tras señalar que las huelgas surgen con más frecuencia y con más violencia allí donde no hay organización obrera (sic) afirmaba que «antes de llegar a la huelga es necesario apurar todos los medios de la 
serena y ecuánime discusión y a medida que pase el tiempo y el movimiento obrero aumente su potencia numérica, económica y cultural, las huelgas serán menos frecuentes y menos dolorosas». Apenas cabe añadir que la huelga no aparecía planteada como arma de lucha política.

\section{Efectivos socialistas durante la Dictadura}

\begin{tabular}{lll}
\hline Año & U.G.T. & P.S.O.E. \\
\hline 1923 & 210.617 & $\left(^{*}\right)$ \\
1924 & $210.915(1)$ & \\
1925 & 217.386 & \\
1926 & 219.396 & \\
1927 & 223.349 & 7.940 \\
1928 & $141.269(2)$ & 8.207 \\
1929 & 258.503 & 12.757 \\
\hline
\end{tabular}

(*): para 1923/4 Tunón de 8.215, Martinez Cuadrado 9.089 y Maurín con datos, según él tomados de El Socialista da para el 31 de diciembre de 1924 5.395; Tuñón da 8.251 para 1928 y 13.181 para 1929. Martínez Cuadrado 7.940 para 1928. Los datos que figuran en el cuadro tienen como fuente: para 1927 y 1928 los datos de la Memoria y de las Actas del Congreso de 1928; los datos para 1927 son a 31 de diciembre y para 1928 el número de representados + no representados en el Congreso (junio-julio). Para 1929 los datos son a 31 de diciembre y están tomados de El Socialista de dicha fecha. Según esta misma fuente, si añadimos los afiliados individuales los datos serían: 7.951 para 1927 y 13.193 para 1929.

(1): los datos de 1923 a 1927 son los ofrecidos por Maurin, que cita estadísticas del Secretariado de la U.G.T. (Los hombres... página 197). Tuñón de Lara, sin embargo, da para 1924, 210.742. En cualquier caso la diferencia es insignificante.

(2): este era el número de afiliados representado en el XVI Congreso (10-15 septiembre 1928) si bien la U.G.T. decia tener 210.567 .

E1 tema de las relaciones entre los socialistas (P.S.O.E. y U.G.T.) y la Dictadura ha sido, desde entonces, polémico y normalmente solventado en torno a la visita rendida por Llaneza al Dictador y a la aceptación por Largo Caballero de un puesto en el Consejo de Estado. Sin embargo plantea sugestivas cuestiones sobre la táctica y la estrategia así como sobre el carácter del socialismo español durante estos años $\left(^{*}\right)$.

Al conocerse en Madrid el golpe de Estado, reunidas extraordinariamente las C.E. del Partido y de la Unión, elaboraron y publicaron un documento firmado por Pablo Iglesias y Francisco Núñez por el P.S.O.E. y Largo Caballero y Besteiro por la U.G.T., en el que tras señalar que «ningún vínculo de solidaridad ni siquiera de simpatía políticam les ligaba al Gobierno

(*) Debo expresar mi agradecimiento a Enrique Moral Sandoval, quien trabaja en una tesis doctoral sobre este tema, a quien debo el acceso a parte de la bibliografia especifica utilizada. 
golpeado, pedian al pueblo que no secundaran a los levantados, tratando más bien de aislar la sedición. El 15 de septiembre, reunidas de nuevo, tomaron el siguiente acuerdo:

11. ratificarse en los acuerdos publicados el día 13 ,

2. ${ }^{-}$reiterar a la clase trabajadora la necesidad de abstenerse de tomar cualquier iniciativa a que pudiera ser invitada por impacientes de buena fe o por elementos que aspiren, con apariencias engañosas, a lanzar al proletariado a movimientos estériles que puedan dar pretexto a represiones que ansía para su provecho la reacción,

3. hacer constar nuevamente que estos Comités proceden con independencia de toda organización ajena al Partido Socialista y a la U.G.T. y reclaman para sí exclusivamente la responsabilidad de las instrucciones que en este momento dan a sus afiliados y simpatizantes, así como recabarán las que puedan dar en circunstancias distintas, si éstas les aconsejasen a variar de conducta.»

Días después, en nota oficiosa, negaban que el Partido y la Unión hubieran autorizado a nadie para declarar movimientos ni algaradas que no creían oportunos en orden a la propia supervivencia del movimiento obrero. Al tiempo rechazaban la propuesta de frente único que se les habia formulado.

Esta línea de conducta fue juzgada de distintas formas. Para Maurín el golpe debió ser "previsto y obstaculizado por la clase trabajadora» y aquél hubiese fracasado «si ésta hubiese contado con un Estado Mayor medianamente inteligente» (28). ¿Cómo?: «a través de la huelga general en Barcelona y en Madrid». Ramos Oliveira presentaba el análisis opuesto: enfrentarse con una huelga revolucionaria al levantamiento hubiera sido un suicidio, un descalabro histórico para la clase obrera, lo que a la postre hubiera cambiado el caracter de la Dictadura (29). De suicidio habria calificado también tal actitud Gabriel Morón (30), si bien consideraba la expresada en el primer manifiesto como un «vago encogimiento de hombros que en tales instantes equivalía a una lamentable inhibición"; hubiese hecho falta según Morón, «una declaración de principios sin postergación del más ahincado propósito de lucha defensiva - cóndicionada a una posible y necesaria asistencia de opinión- contra toda extralimitación de fuerza

(28) Joaquín Maurín: Los Hombres de la Dictadura, Madrid 1930, págs. 153 y 154.

(29) Antonio Ramos Oliveira: Nosotros..., pág. 179; y «El Socialismo Español de 1909-1934», Rev. Leviatán, año I, n. ${ }^{\circ}$.

(30) Gabriel Morón: El Partido Socialista ante la Realidad Politica Española, Madrid 1929, págs. 78 y 79 . 
por parte del Poder»; para Ramos, se había cumplido con el «vibrante» manifiesto. Ya en el campo apologético, Enrique de Santiago (31) afirmaba que el Partido y la Unión hicieron frente «al movimiento sedicioso de Primo de Rivera en aquel vibrante manifiesto... definiendo claramente la actitud de resistencia pasiva que, observada sabiamente por espacio de siete años, creó el ambiente que puso fin a la dictadura militarista para que nunca más pudiera retoñar».

Ciertamente, la actitud a tomar por los socialistas era dificil. Ante una dictadura militar no solo triunfante sino ampliamente aceptada no cabía el recurso del choque frontal. Los socialistas, atravesaban además un periodo delicado a causa de la escisión comunista, que no sólo afectó a su estructura sino que se dejaría sentir en sus planteamientos políticos. Por último, el carácter temporal con el que se autodeclaraba la nueva situación añadía un motivo más a la vacilación.

Esta, la vacilación, es la nota característica de los primeros meses en los que tiene lugar el encuentro Llaneza-Primo de Rivera (1. ${ }^{\circ}$ de octubre) y la aceptación de ciertas concejalías a las que habían accedido los Vocales asociados, como consecuencia del R.-D. de 30 de septiembre que disolvía los Ayuntamientos (Gaceta, $1 .^{\circ}$ de octubre).

Vencida «la letra a noventa dias» el Comité Nacional del partido marca ya, el 9 de enero de 1924, una línea de conducta política:

«Por unanimidad se decide que los socialistas no acepten cargos públicos que no sean de elección popular o representación oficial de organismos obreros y designados por estos directamente, rigiendo este acuerdo con carácter nacional a partir del momento en que se adopta».

Mientras tanto, como ha señalado Elorza (32), la C.N.T. había mantenido ante el golpe una actitud de expectativa y «promesa tácita de neutralidad si los militares en el poder respetan la situación previa de la clase obrera». Sin producirse su declaración de ilegalidad se incrementó, desde luego, la presión policial sobre los Confederados, cuya evidente crisis durante el período habría que atribuir fundamentalmente a sus desgarros internos.

El Estatuto Municipal aprobado por Real D.-L de 8 de marzo de 1924 ofreció la primera piedra de toque seria a la norma de conducta emanada

(31) Enrique Santiago: La U.G.T. ante la Revolución, 1932, pág. 18.

(32) A. Elorza: "Anarcosindicalismo Español bajo la Dictadura 1923-1930", Rev. de Trabajo números 39-40, así como Rev. de Trabajo, números 44-45. 
por el Comité Nacional. Establecía en su artículo 43 que en los Municipios de más de 1.000 habitantes habría Concejales de elección popular y Concejales de representación corporativa, designados por las Corporaciones o Asociaciones que figurasen en el censo especial que a tal efecto se instituía y en el que figurarian (art. 72) Corporaciones, Asociaciones, Sindicatos, Hermandades y otros. Por otra parte el artículo 71 declaraba obligatoria tal representación corporativa alli donde existiesen tales entidades, so pena de ser sancionadas, entre otras, a la pérdida de sus derechos representativos y profesionales. $Y$ el 31 de marzo, reunidos conjuntamente los Comités Nacionales del Partido y de la Unión, tras «considerar improcedente, entre otras cosas, lo estatuido acerca del voto corporativo", y ante la obligatoriedad del ejercicio de la representación, pedían a las Sociedades adheridas al Partido y a la Unión con derecho a voto, la inscripción en el censo y el nombramiento de concejales que les correspondiese. No existía ninguna contradicción formal con la línea marcada.

Y llegamos al controvertido asunto del Consejo de Estado. Por R.-D. de 2 de junio de 1924 el Pleno y el Consejo de Dirección del Instituto de Reformas Sociales pasaban a ser el Consejo de Trabajo y la Comisión Permanente del mismo; en delegaciones de éste quedaban convertidos los Institutos regionales y las Juntas locales y provinciales de Reformas Sociales. Y por R.-D. de 19 de junio (Gaceta del 22) se organizaba el recién creado organismo. En su artículo $5 .^{\circ}$ establecía que 16 de sus 59 Vocales (en pleno) serían representantes del elemento obrero, elegidos por las Asociaciones profesionales existentes. Otro R.-D. (de 13 de septiembre. Gaceta del 14) reorganizaba el Consejo de Estado, incorporando al mismo, entre otros, dos miembros - uno patronal y otro obrero- del Consejo de Trabajo, a designar por el presidente del mismo. Era evidente el choque entre la disposición legal y la norma de conducta. El 22 de septiembre (33) la representación obrera propuso a Largo Caballero «siguiendo la práctica establecida en el Instituto de Reforma Social y el criterio constante de no aceptar representación alguna que no proceda de la clase a que pertenecen». El Presidente aceptó el procedimiento seguido, no sin sentar que ello no podía implicar «renuncia ni declinación de prerrogativas que a la Presidencia han sido atribuidas»; y que, obviamente, podía recabar en cualquier momento. Formalmente, además, era él quien los había designado, por más que se desentendiera de lo que, en definitiva, eran cuestiones internas de los representantes obreros.

(33) Francisco Largo Caballero: Presente y Futuro de la Unión General de Trabajadores de España,. Madrid 1925, págs. 44 y ss. 
Prieto y De los Ríos se opusieron, por motivos políticos, en cartas a la Ejecutiva, a que un socialista aceptase el cargo de consejero de Estado. Pero Largo Caballero tomó posesión el 25 de octubre, el mismo día en que aparecía en la Gaceta el R.-D. por el que se aprobaba el Reglamento para el Régimen Interior del Consejo. Simultáneamente presentaba Prieto su dimisión como vocal de la Ejecutiva. El Comité Nacional del Partido aprobaba la participación el 10 de diciembre. No hubo, ni mucho menos, unanimidad, porque si bien De los Ríos fue el único miembro de la Ejecutiva que votó en contra, a él se unieron cuatro delegados regionales, por seis que la aprobaron. En total 14 votos a favor y 5 en contra. Pero la cuestión no quedó definitivamente clausurada, ya que en el XII Congreso ordinario del Partido (28 de junio-4 de julio de 1928) fue objeto de una vivísima polémica (34).

La Agrupación de Valladolid había propuesto que, aun considerando que la clase trabajadora organizada debía tener adecuada representación en el Consejo, ningún socialista podría formar parte del mismo mientras no se observase para su nombramiento los medios democráticos de elección corriente en estos casos. Y, ya en el Congreso, la Ponencia sobre cuestiones de táctica presentó el siguiente texto:

«Se declara la conveniencia de que la clase trabajadora tenga representación adecuada en el Consejo de Estado y en consecuencia se autoriza a los representantes del Partido para que mediante la designación de la organización obrera a quien corresponda, puedan formar parte de dicho organismo»

Firmaban: Enrique Francisco, Wencelao Carrillo, Pascual Tomás, Luis Arráez, Moisés S. Gali y Emilio Martínez. A esta propuesta formulaban José Ruiz del Toro, Teodomiro Menéndez, Gabriel Morón, Romualdo R. de Vera y Bernardo Aladrén, en voto particular el criterio de que, tanto por razones de principios y eficacia socialista como de eficacia y oportunidad política, el Congreso debía acordar que los afiliados al Partido no pudiesen aceptar representaciones en organismos de carácter politico.

La discusión fue muy viva. Largo Caballero no aceptaba la calificación de "político" si con ello se quería establecer diferencias entre el Consejo y los Ayuntamientos, Comités Paritarios, etc. Todo tenía carácter político y lo importante, continuaba, no era que se hiciese politica o no, sino que la que se hiciera fuera política socialista $y$ eficaz. Tal eficacia era

(34) Memoria y Actas del XII Congreso, Madrid 1927 y 1929. 
totalmente discutida por Prieto -en otro momento del Congreso- quien veía en la censura el arma del Gobierno contra la posible propaganda a que pudiera dar origen la actuación de Largo. Mientras para Mora Requejo el cargo no era meramente consultivo, Arráez entendía que no se estaba ante un organismo puramente político, sino prolongación de otros, de carácter consultivo o económico, en los que necesariamente había de tener representación la clase obrera. En la misma línea se pronunció Sánchez-Rivera; Del Toro venía a decir: ¿colaboración? No. ¿Asesoramiento en órganos políticos? Tampoco.

Pero la cuestión de fondo, no debatida ampliamente en el Congreso, afectaba a las relaciones P.S.O.E.-U.G.T. Buena parte del nerviosismo de las derechas «constitucionales» y del republicanismo consistía en que, cercenada la actuación de los partidos políticos por la Dictadura, no contaban con Sindicatos o Corporaciones con los que mantener una presencia en el ámbito político. Los socialistas lo estaban haciendo a través de la Unión. Pero ello entrañaba el peligro de que la táctica socialista viniese determinada por una organización cuyos fínes no eran los mismos que los del partido. Unidos en la cumbre por prácticamente el mismo personal de dirección, había un evidente peligro en que los "socialistas" se retirasen de todos los cargos sin que ello implicase que no acudiese a ellos la Unión, que por su política y sus fines proclamaba la asistencia alli donde hubiese representación obrera. Largo Caballero lo vio asi; por una parte el Partido no tenía ninguna representación, sino la Unión, y aquel no tenía facultades para condenar a ésta a la inacción; por otra parte, un acuerdo en este sentido equivaldría a que los elementos socialistas de la organización sindical abandonaran la dirección en manos de quienes no lo fueran. Pla y Armengol habría añadido a este respecto que un P. Socialista sin una organización obrera no es nada: una mariposa que no tendría donde posarse. T. Menéndez -el gran vapuleado del Congreso - sostenía la necesidad de diferenciar vigorosamente el campo político del sindical y si bien mantenía la necesidad de que la U.G.T. acudiese a todas las instituciones de carácter económico y sindical, a riesgo de ser desplazada por Libres, Amarillos, etc., recordaba que se encontraban en un Congreso socialista de carácter eminentemente político y que el Partido debía orientar a la clase trabajadora: «el interés del socialismo está por encima del interés sindical».

Sometida definitivamente la cuestión al dirimente arbitraje de las urnas, el Congreso aprobó la continuidad en el cargo de Consejero del Estado por 5.235 votos contra 593. Asimismo se aprobaba la permanencia de los concejales corporativos por 5.288 votos a favor contra 490 . Días después el XVI Congreso de la U.G.T. aprobaba que: 
«No habiendo variado las causas que aconsejaron al Comité Nacional de la U.G.T. la aceptación de un puesto en el Consejo de Estado en representación de la clase obrera española, considera esta Ponencia que no procede la retirada, como propone la organización de Cheste, de nuestro representante en el citado organismo consultivo».

Había triunfado la que Tuñón de Lara denomina «corriente social-ugetista».

Mientras tanto el Directorio militar había dado paso a un Gobierno civil presidido por Primo de Rivera (3 dic. 1925) y en el que figuraban los tres ministros «innovadores» de la Dictadura: Aunós, Calvo Sotelo y el Conde de Guadalhorce. Habia tocado techo la popularidad del Dictador con la pacificación de Marruecos tras el desembarco de Alhucemas (8 set. 1925); había surgido la U.P. e incluso se había dominado el levantamiento de la noche de San Juan (24 jun. 1926) (35); había aparecido el decreto que creaba la Organización Corporativa. La muerte de Pablo Iglesias -9 dic. 1925- había supuesto un auténtico trauma sentimental en el seno del socialismo español. Al margen ya de su autoproclamada limitación temporal, la Dictadura se enfrentaba con la cuestión de su salida. Para ello concibió Primo de Rivera la Asamblea Nacional Consultiva, a la que se había referido con anterioridad varias veces antes de que apareciese en la Gaceta del 14 de set. de 1927 el R-D.-Ley de 12 del mismo mes que la creaba. "No ha ser Parlamento - decía la exposición de motivosno legislará, no compartirá soberanías. Pero por encargo del Gobierno y aún por iniciativas propias, colaborará en su obra con carácter e independencias garantizadas ipor su origen! (la exclamación es mía) por su composición y por sus fueros".

Estaria compuesta por un representante municipal y otro provincial, de cada provincia. Un representante por cada organización provincial de la U.P., representantes del Estado a quienes se confiriese carácter de asambleísta, representantes por derecho propio en virtud de las categorías que se ostentasen o cargos que se ejercieran $\mathrm{y}$, por último, representantes de la cultura, la producción, el trabajo, el comercio y demás actividades de la vida nacional, designados libremente por el Gobierno (art. 20). La Asamblea debería "preparar y presentar escalonadamente al Gobierno, en un plazo de tres años y con carádter de anteproyectos, una legislación general

(35) Para los intentos de golpes durante la Dictadura, véase Vicente Marco MiRanda: Las conspiraciones contra la Dictadura, Madrid, 1930. 
y completa que a su hora ha de someterse a un sincero contraste de opinión pública $y$, en la parte que proceda, a la Real sanción.» El número de asambleístas no sería menor de 325 ni mayor de 375 (modificado por R.-D. de 22 de set. - Gaceta del 28 - por el que se ponía el límite máximo en 400). En la Gaceta de 21 de set. aparecía su Reglamento provisional. Su presidente Yanguas Messía hizo hincapié en la sesión inaugural (10 oct. 1927) en el carácter de la Asamblea: «ni en la mente del Gobierno germinó, ni la Asamblea puede alentar nunca el propósito de cercenar, ni menos anular las altas facultades del P. Legislativo» (36).

El Gobierno, según el artículo 20 nombró 6 socialistas para la Asamblea: Largo Caballero, Lucio Martínez, Santiago Pérez, Francisco Núñez Tomás, Fernando de los Rios, y Manuel Llaneza; incluso se permitió el rasgo homorístico de nombrar a Dolores Cebrián, esposa de Besteiro, ya que el artículo 15 del D. de creación establecía que las mujeres casadas podían ser asambleístas si eran "debidamente autorizadas por sus maridos» y siempre que los mismos no perteneciesen a la Asamblea. El Partido y la Unión convocaron Congresos extraordinarios para tratar de los problemas que planteaba la convocatoria de la A.N.C.; en el del Partido estuvieron representadas 106 Agrupaciones y 5.026 afiliados. El Comité Nacional propuso al Congreso que los socialistas no pudiesen aceptar esos cargos, aprobándose un dictamen de clara repulsa; en él se decia:

«El P.S.O.E. protesta con toda energía y sin la más mínima reserva contra el régimen de dictadura imperante desde hace cuatro años. Protesta igualmente contra la creación de la A.N., de la que ningún militante en nuestras filas podrá formar parte, congratulándose de coincidir así con la resolución adoptada ayer en el mismo sentido por la Unión General de Trabajadores.

Y declara la imperiosa necesidad de que el país se rija por normas de libertad sinceras y amplias que permitan el desenvolvimiento de nuestros ideales y consientan que en la gobernación de España se refleje fielmente la voluntad nacional, invocada con frecuencia, pero no consultada por procedimientos democráticos que hagan conocer sus verdaderos designios y obliguen a respetarlos». Madrid, 8 de octubre de 1927.

(36) José Yanguas Messfa: Discurso inaugural de la Asamblea Nacional Consultiva. Diariode las Sesiones de la Asamblea Nacional Consultiva, 10 oct. 1927. 
El acuerdo tomado el dia anterior por la U.G.T., era el siguiente:

"Que no ha lugar a que se acepte por afiliados a la U.G.T. puestos en la A.N. creada por R.-D. de 12 de septiembre último y que a la vez lamenta que el carecer de una libertad indispensable a cuya plenitud aspira, le impida razonar debidamente ante la opinión pública su resolución».

Ninguno de los designados aceptó el puesto.

Al margen los socialistas del organismo encargado de preparar reformas institucionales que abrieran paso a un régimen de "normalidad», la Unión desplegó sus esfuerzos en el terreno de la Organización Corporativa, que había sido acogida con beneplácito desde el primer momento. Y no solamente fue defendida $-y$ exigida su puesta en práctica - a partir de noviembre de 1926, sino aún caida la Dictadura. Así lo hacía Enrique Santiago en 1932 (37); el mismo año Ramos Oliveira (38) consideraba los comités paritarios «como la medida dictatorial que más favoreció al movimiento obrero español», propició la propaganda y gracias a ellos «aumentaron los efectivos de la U.G.T. y se vertebraron mejor los existentes». Los socialistas vieron en ellos «el principio de una eficiente organización corporativa». "Por ellos se hacía forzosa la organización de la clase trabajadora». Criterio opuesto era el de Maurín, en su apasionado y a veces erróneo e injusto libro; pero Maurín tenía razón al considerar que los comités paritarios eran el intento llevado a cabo por la Dictadura de atar a su carro a las masas obreras (39).

Lo que no implicaba que no fueran aprovechables; lo que explica, a su vez, ciertos temores patronales, e incluso el frenazo a implantarlos en el campo pues daba una ocasión propicia a la organización del campesinado. También a posteriori, Martín Artajo (40) criticaria el ensayo de Aunós por haber abierto los organismos paritarios a los «sindicatos marxistas de lucha de clases» sin "exigirles garantías de que no iban a convertirlo en trincheras para un ataque a la sociedad capitalista». Claro que a continuación añadía que «la C.N.T. se cobraba con la acción directa lo que en el comité le sacaba la U.G.T.» (sic.)

(37) E. Santiago, op. cit., pág. 25.

(38) Ol.iveira Ramos: Nosotros..., págs. 192 y ss.

(39) MaUrín, op. cit., págs. 187 y ss.

(40) Citado en Corporativismo de Sancho Izquierdo, Prieto Castro y Muñoz Casayús. Zaragoza 1937, pág. 169. 
Pues bien, la labor propagandista alcanza su cenit en 1929; y Largo Caballero constantemente define la postura de la U.G.T.: "Los Comités Paritarios pueden llevarnos a unos resultados que el Gobierno interpreta de un modo y nosotros, de otro" (41). La U.G.T. -continuaba Largoreconocía que la huelga no era un arma que pudiera manejarse sistemáticamente sino que debian intentarse todos los medios de solución antes de llegar a ella; estos antagonismos, seguía, debían y podian tener solución, ahora, en los Comités Paritarios y por ello la U.G.T. estaba conforme con dichos organismos.

Como vemos, la postura de Largo con respecto a la huelga no distaba gran cosa de las de Cordero y Saborit, a las que nos hemos referido anteriormente. En 1925, en "Presente y futuro de la U.G.T.» sólo habría subrayado el párrafo "bien organizada» con que concebía la huelga el artículo $2 .^{\circ}$ de los Estatutos de la Unión, para diferenciarla del espontaneísmo anarquista.

Además, la U.G.T. tenía la oportunidad de copar tales Comités, favorecida sin duda por la situación de los anarquistas durante la Dictadura y por la postura antiintervencionista de aquellos (no en bloque, como señala Elorza). A ello aludía también Largo Caballero en su discurso ante el Congreso de la Federación gráfica española (42):

«Hay que tener en cuenta que esa organización puede ir a manos de otros elementos, contra lo cual hay que defenderse y lo menos que podemos hacer es tener en nuestras manos ese organismo para que no nos cause daño.»

Pero, paralelamente al intento de institucionalización, la oposición a la Dictadura se había ido incrementando; fracaso del golpe decimonónico de Sánchez Guerra (43); oposición universitaria; desorganizada pero cada vez mayor actividad de los republicanos que, tras el intento de agrupación que supone la Alianza Republicana el 11 de febrero de 1926 (44), se habian dispersado de nuevo. Marañón, Jiménez Asúa, Pérez de Ayala, Marcelino Domingo, Alvaro de Albornoz, entre otros, habían abandonado la Alianza que quedaba bajo los auspicios de Lerroux «que tomó a su cargo la reorgani-

(41) Conferencia en Zaragoza. El Socialista, 3 enero.

(42) “La U.G.T. y el interés general del país», Boletín de la U.G.T., oct. 1929.

(43) Véase: Rafael Sánchez Guerra: El Movimiento Revolucionario de Valencia, Madrid 1930.

(44) Alianza Republicano, el 11 de febrero de 1926. Manifiesto, Madrid 1926. 
zación inmediata bajo nuevas bases» (45); la crisis económica y la desafortunada intervención en los cambios, que costaría el puesto a Calvo Sotelo dias antes que al Dictador, enfrentaba ahora a la Dictadura con sectores que le habían mostrado su «neutralidad». Un anticipo de ella había sido la polémica Primo de Rivera-Cambó sobre el valor de la peseta en diciembre de 1928; hasta divergencias entre la corona y el Gobierno ya que la primera empezaba a considerar peligrosa para su supervivencia la continuidad del segundo. Largo Caballero a principios de 1929 (46) reconocía que los Comités Paritarios no compensaban la falta de libertad política. Y elaborado ya el proyecto constitucional El Socialista expresaba claramente su oposición al mismo (47); los socialistas querían una Constitución no otorgada sino elaborada en el seno de unas Cortes Constituyentes a las que habría que convocar a través del sufragio universal, en un ambiente de amplia libertad. Y se manifestaban por una República electiva, federal de acuerdo también con el procedimiento del sufragio. Sabido es que Primo de Rivera pretendía aprobar el proyecto a través de un plebiscito.

Ante la toma de posiciones, el socialismo necesitaba expresar, en una decisión política, sus distancias respecto a la Dictadura; y la ocasión la ofreció Primo de Rivera en un increible error político. Magno error era, sin duda, of recer a altas personalidades politicas y a importantes Instituciones de la vida nacional puestos en la Asamblea, bien por razón de cargos ostentados antes del 23, bien por designación de las propias instituciones, sin haberlo negociado o tanteado anteriormente con unos y con otras. Las negativas de los primeros y la oposición mostrada en las segundas dejaban a la Dictadura aislada y maltrecha, empujándola a su definitivo desplome.

El 30 de julio de 1929 aparecía en la Gaceta el R.-D.-Ley del 26 por el que el Dictador ampliaba la A.N.C., buscando asistencias para el último año de vida de la misma, a fin de que en el epílogo de la Dictadura colaborasen «todos aquellos que por sus conocimientos» fueran «capaces de aportar ideas y experiencias que avaloren la obra que se ha de realizar». Llamaba a la Asamblea a los ex-Presidentes del Consejo de Ministros, de las Cámaras y del Consejo de Estado, «por creer firmemente que esta

(45) F. Villanueva: El Momento Constitucional, Madrid 1929, pág, 82.

(46) «Hay que prepararse», Boletin de la U.G.T. año I, n. 1, enero 1929; aparece también en El Socialista del 24 de enero de 1929.

(47) Entre los numerosos editoriales referentes al tema, cabe destacar: «El problema constitucional», 23 de jun., "El presente momento politico de España», 9 de jul., «Por los fueros de la democracia», 19 de jul., y «El proyecto de la Asamblea, no; pero la Constitución del 76, tampoco", 26 jul. 
invitación no es una claudicación ni para el régimen gobernante ni para los políticos del derrocado" sino una necesidad del momento, en el que el Gobierno excluía "visiones unilaterales». Dando este paso la Dictadura mostraba el estado de descomposición en que se hallaba. Concedía también cinco puestos a la U.G.T., dos a los Libres y dos a los Católicos, así como otros a Academias, Universidades, Colegios de Abogados de Madrid y Barcelona, etc. La novedad estribaba en que éstos serían designados libremente por las entidades respectivas, de acuerdo con sus normas estatutarias.

Por el capítulo de los ex-presidentes se opusieron radicalmente Melquiades Alvarez, Sánchez Guerra y Manuel Villanueva. Sánchez Toca y Romanones estaban indecisos, más bien partidarios, pero al final renunciaron. Al parecer, estos dos últimos no se oponían si se les designaba por sus respectivas Academias (48). Sánchez Toca, elegido por la Academia de Ciencias Morales y Políticas, declinó también. No fue ninguno de los ex-presidentes. Las votaciones en algunas corporaciones fueron actos antidictatoriales; el Colegio de Abogados de Madrid votó a ¡Sánchez Guerra, Santiago Alba y Eduardo Ortega y Gasset! un detenido y dos exiliados; la Universidad de Valladolid a Unamuno, exiliado también y que con E. Ortega y Gasset editaba, en París, «Hojas Libres».

La U.G.T. se enfrentaba con un delicado problema. Dispuesta globalmente a estar presente alli donde ella pudiera elegir a sus representantes ¿qué excusa podía ofrecer para no enviarlos a la Asamblea? La resolución del problema comporta, como veremos a continuación, un viraje táctico de los socialistas. Reunido el Comité Nacional el 12 de agosto (49), Largo Caballero quiso hacer valer el acuerdo tomado en el Congreso extraordinario de 1927, cuando, obviamente, los planteamientos entonces y ahora eran muy distintos. Reconocía que el Decreto resolvía ciertas cuestiones de procedimiento y que el asunto para el que eran llamados - discusión del proyecto constitucional-- era de singular trascendencia para el país. Besteiro se mostró favorable a ocupar los puestos, pues su negativa en el Congreso se había basado «única y exclusivamente en la circunstancia de que a la Unión General se le negaba la posibilidad de elegir libremente sus representantes». El retraimiento era un error, continuaba Besteiro, aunque se cosecharan de momento plácemes y aprobaciones. $Y$ apuntaba que hubiera sido preferible convocar otro Extraordinario, a lo que se oponían Caballero, Trifón Gómez y W. Carrillo quien, siendo partidario de acudir, cambiaba de posición

(48) F. Villanueva: El momento..., pág. 53.

(49) Boletín de la U.G.T., agosto 1929. 


\section{ARTICULOS}

con tal de no votar el Congreso. Curiosamente tales oposiciones se basaban en que convocarlo podría dar a entender que unos cuantos interesados en ocupar sitios en la Asamblea querían manipular y torcer la voluntad de la clase trabajadora.

Ciertamente habia existido siempre una tendencia a exceptuar de la A.N.C. la línea de representación, por cuanto ésta sustituia al Parlamento, órgano de la soberanía popular.

Sin embargo, fue Saborit quien exresó claramente la cuestión: «Ahora, en un momento en que el proyecto de Constitución 'está ya hecho, y a sabiendas de que no podremos modificar nada, el ir, aunque hiciéramos alli lo que quisiéramos, seria hundirnos políticamente ante el pais, sin mérito alguno". Y ésto lo decía Saborit, quien en el Congreso ordinario, interrumpiendo la disertación de Gabriel Morón, cuando éste se preguntaba si se habría acudido a la A.N.C. si se hubiese nombrado de otra manera, habia exclamado: "A mí no me avergüenza decir que yo sí». Cordero añadía: «Nuestra intervención en la Asamblea no daría como consecuencia la reforma del proyecto de Constitución y, moralmente, nos produciría un gran daño».

En fin, puesta a votación se aprobaba la resolución presentada por Largo Caballero:

«Reunidos el Comité Nacional de la U.G.T. de España ha examinado, con la atención que merece el D.-Ley de 26 de julio último, por el cual se concede a este organismo el derecho a designar libremente cinco representantes para formar parte de la A.N.C. $\mathrm{y}$ visto el acuerdo tomado por unanimidad en el Congreso extraordinario celebrado en Madrid el 7 de octubre de 1927 en el que se dice: "Que no ha lugar a que se acepten por afiliados a la U.G.T. puestos en la A.N.C." y considerando que no está en sus atribuciones derogar dicho acuerdo, resuelve atenerse al mismo $\mathrm{y}$, por tanto, no designa ningún representante para la tan repetida Asamblea».

Votaban en contra Besteiro y Enrique Santiago.

El acuerdo adoptado suponía planteamientos políticos a los que se sacrificaban las cuestiones de procedimiento. Los socialistas, conscientes de la agonía de la Dictadura, intentaban alejarse lo más posible de ésta, aún con ciertas contradicciones. En ese camino se insertaba el manifiesto que redactado por una Comisión de las Ejecutivas del Partido y de la Unión, fue aprobado por el Comité Nacional de ésta última en la citada reunión del 12 de agosto. «Prohibida su publicación por la censura, corrieron de 
mano en mano miles de ejemplares, siendo comunicado por clave a los grandes rotativos periodísticos del mundo entero... haciéndose una tirada [a multicopista] de 6.000 ejemplares." (50).

El Manifiesto a la opinión pública rechazaba derminantemente el anteproyecto de Constitución "por su origen antidemocrático y por el falso plebiscito con que se trata de darle una apariencia de sanción popular». "Nosotros aspiramos - decía también- pará realizar nuestros fines a un Estado Republicano de libertad y de democracia, donde podamos alcanzar la plenitud del poder político que corresponde a nuestro creciente poder social. Queremos ser una clase directora en los destinos nacionales y para eso necesitamos de condiciones políticas que nos permitan llegar democráticamente, si ello es posible, a cumplir esa misión histórica".

El manifiesto mereció de Villanueva - director de El Liberal y autor de varios libros sobre esta coyuntura histórica- encendidos elogios. Según él los socialistas se habían rehabilitado ante la opinión democrática y el Partido Socialista aparecía como el supremo recurso de la democracia española para restaurar las libertades públicas.

Los socialistas, en efecto, habían tomado posiciones, no sin dar, de vez en cuando, muestras de "prudencia" y "realismo" ante ese futuro incierto. Todavía el 31 de diciembre Largo Caballero se preguntaba con respecto a 1930: «¿Se verificarán elecciones a fin de constituir definitivamente los Ayuntamientos y las Diputaciones? ¿Se elegirá un nuevo Parlamento? En caso afirmativo ¿qué papel desempeñará la clase obrera organizada en esos acontecimientos? ¿Habrá en dichos organismos representación corporativa?... Si eso sucediere, queramos o no, ello llevará consigo el que la Unión y el Partido se verán impulsados a participar, con una intensidad imposible de calcular ahora, en la vida integral de España.» (51). Y concluía con una pregunta-respuesta de indudable interés: «...Si alguna de las hipótesis enunciadas anteriormente llegan a ser realidades ¿Convendría a los intereses de la clase trabajadora y a los de la nación en general que esa autonomía e independencia [la de la U.G.T. y P.S.O.E. en la acción política parlamentaria] continúe o que, con el fin de que la actuación política parlamentaria sea unificada y eficaz, se forme con ese objeto una "unidad" no solo espiritual, sino "orgánica" aunque ello obligue a modificar la estructura de los "órganos" directores del Partido y de la Unión?»

Aquí estaba la propuesta de seguir la senda del laborismo, proyecto que, según Maurín, anidaba en Largo Caballero desde tiempo atrás.

(50) E. Santiago: La U.G.T. ante...

(51) "Mirando hacia el mañana», El Socialista, 31 dic. 
Justamente el 31 de diciembre el Rey restaba su apoyo al proyecto de salida elaborado por Primo de Rivera: dar paso a un régimen transitorio que debería ser preparatorio del definitivo y de duración no superior a tres años. La Dictadura debería permanecer solo unos meses más y el gobierno transitorio preparar una normalidad constitucional en base a una nueva Constitución y nuevas leyes complementarias, emanadas de una nueva Asamblea, parte procedente de la ya existente, parte electiva (52). El Rey le instaba a llevar a cabo, a cambio, la renovación parcial de Ayuntamientos y Diputaciones, agotar el plazo de vida legal de la A.N.C. y decidir entonces si prorrogar su vida, sustituirla por otra de composición y origen distintos o restablecer la vida parlamentaria, aún con modificaciones en la expresión del sufragio. Todavía Primo de Rivera quiso llevar a cabo esta segunda

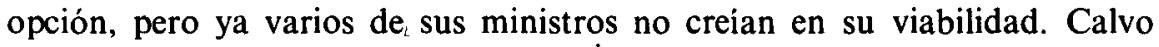
Sotelo dejaba de ser ministro el 20 de enero; el 26 se publicaba la nota oficiosa en la que se explicaba al país que el Dictador había pedido a los diez Capitanes Generales, jefe de las fuerzas de Marruecos, tres Capitanes generales de departamentos marítimos y directores de Guardia Civil, Carabineros e Inválidos que le manifestasen si contaba con su confianza, para dimitir en caso contrario (53). Ante las contestaciones evasivas presentaba su dimisión, que le era aceptada.

Al día siguiente de constituirse el Gobierno Berenguer, los socialistas elaboraban un manifiesto (prohibido por la censura, pero profusamente distribuido) en el que expresaban que su actuación «ante las necesidades inmediatas de la vida política no tiene por qué desviarse de la línea de conducta observada hasta aqui. Nosotros en ningún caso nos retiramos al Aventino. Actuaremos en la medida que lo permitan nuestras fuerzas y las circunstancias exteriores. Si se restablecieran más o menos parcialmente las libertades suspendidas, las utilizaríamos como medios de lucha y en todo caso procuraremos desarrollar nuestra actuación allí donde nuestros correligionarios y el voto de los conciudadanos nos envíen con una representación legítima.» (54).

¿Colaboración? ¿Uso correcto de las condiciones políticas imperantes? Los socialistas dirían que el P.S.O.E. no pudo colaborar por cuanto no estuvo representado en ninguna parte; la U.G.T. sí y no solo en el Consejo de Estado sino en la Comisión Permanente de Enseñanza Industrial, Consejo

(52) Documento presentado por Primo de Rivera al Rey. Calvo Sotelo, op. cit., págs. 342 y ss.

(53) Dionisio Pérez: La Dictadura a Través de sus Notas Oficiosas, Madrid 1930, págs. 321 y ss.

(54) E. Santiago; op. cit., pág. 53. 
de Cultura Social, Junta Central de Emigración, Patronato de Ingenieros y Obreros pensionados en el Extranjero, Caja General del Crédito Marítimo, Comisaría Sanitaria, Consejo Interventor de Cuentas del Estado, Comisión Interina de Corporaciones, Consejo de Trabajo, entre otros. No asistieron a la Junta Central de Abastos cuando esta pasó a ser presidida por Martínez Anido ni al Consejo de Economía Nacional, por habérseles asignado una vocalía a la U.G.T. y otra, en igualdad de condiciones, a los Sindicatos Católicos. Fueron a ellos socialistas en tanto que representantes de la U.G.T. y el partido no los desautorizó aduciendo las razones expresadas atrás. ¿Pura distinción formal?

Sería más productivo, incidir en el aspecto de si tal actuación -exceptuemos el Consejo de Estado- era coherente con la linea seguida por la Unión, antes aún de la Dictadura, de estar presente alli donde se debatiesen cuestiones laborales y pudiesen elegir a sus representantes. Los ugetistas reclamaban tal coherencia e incluso la línea seguida por el socialismo de la II Internacional. Pero obviamente las circunstancias políticas españolas eran muy distintas a las de los países a cuya actuación pretendían equipararse. En este sentido iquedaba la política del Partido a expensas de la defensa de los intereses inmediatos de los trabajadores? La cuestión, se planteó en distintos momentos: se trataba de emprender o no una acción política clara contra la Dictadura; en, caso afirmativo el Partido no podía hacerlo, obviamente, en solitario, sino en inteligencia con republicanos y lo que, en aquel contexto, se denominaba «opinión liberal». Esta era la postura de Teodomiro Menéndez, Fernando de los Ríos, Prieto, Morón, Mora Requejo entre otros. La tendencia dominante era opuesta, en el concreto momento político, a tal inteligencia por más que en el Congreso ordinario hiciese aprobar una resolución sobre Alianzas por la que no se cerraba ninguna puerta.

La cuestión la replanteó vivamente un artículo de Alvarez del Vayo aparecido en El Socialista del 1.॰ de mayo, titulado «Sobre la táctica del partido". Para decidir, venía a decir, si un Partido Socialista está a la altura de su misión en un contexto político determinado hay que juzgarlo, bien con el criterio democrático, el de los que ven en el elemento obrero gran factor constitutivo de un régimen de libertad política en el que se realicen progresivamente las reivindicaciones de tipo social y el propio programa socialista, o bien con el criterio de la lucha de clases. El Partido español debía preguntarse si se había ajustado a uno de esos dos criterios; si de ajustarse al primero no cabria una actividad mayor y si por el segundo, si se habian aprovechado las ocasiones para intensificar la lucha de clases.

A partir de este artículo polemizaron Prieto (a través de la agencia 
periodistica Sirval) y El Socialista. En medio se inserta otro artículo de Alvarez del Vayo sobre la táctica (17 mayo), de quien "El Socialista" decía estar "en los linderos del comunismo»; planteaba aquí el problema del reformismo: para éste «la lucha en torno al problema de salarios, del desarrollo de las Cooperativas, y demás conquistas parciales proletarias van convirtiéndose gradualmente en la finalidad misma del movimiento socialista». Afirmaba además que no era sorprendente que la oposición reuniese las alas derecha e izquierda del Partido bajo el afán de una mayor actividad.

Con ello venía a calificar al ala derecha de liberales avanzados y a la dirección y a la política del partido de reformistas. $Y$ en efecto, los planteamientos del ala derecha no diferían básicamente de los liberales, por más que entendiesen acertadamente que sin libertades politicas los socialistas quedaban reducidos a actividades societarias. Prieto consideraba que el papel de los sucialistas consistía en robustecer el liberalismo, sustituirle si fuera preciso en el cumplimiento de su misión. De los Ríos (55) ni creía en la lucha de clases ni era ideológicamente marxista. Para ellos las libertades (democráticas) eran un fin en sí mismas y el socialismo, un plan de conquistas escalonadas.

La dirección, aún a pesar de que Besteiro no había estado afortunado en el Congreso («si esta situación [la Dictadura] se prolonga, que se prolongue; nosotros seguiremos avanzando"), expresaba continuamente en la prensa que los socialistas aspiraban a tales libertades y las consideraban necesarias. Pero el Partido Socialista mantuvo hasta el final sus reticencias a pactar con republicanos y liberales (56). La dirección nunca planteó como objetivo táctico primordial, al que debían dirigir sus esfuerzos las actividades de las organizaciones socialistas, la conquista de tales libertades. Con ello se fijaron su propio techo, que obviamente fue superado con creces cuando éstas fueron recobradas.

(55) De quien Caballero decia que era un "seráfico santo laico antimarxismo». LaRgo Caballero Mis Recuerdos, México, 1954, pág. 90.

(56) Reticencia mantenida después de la Dictadura pues, como señala Prieto V. Zapatero y DE LOS Rios, fueron al "Pacto de San Sebastián" bordeando la disciplina del partido. Fernando DE los Ríos Escritos sobre Democracia y Socialismo, estudio preliminar de V. Zapatero. Madrid 1974, pág. 41. 